\title{
Transformation of the educational environment to ensure sustainable development
}

\author{
Varvara Altunina, and Inobbat Alieva* \\ Immanuel Kant Baltic Federal University, Gorkogo Str., 23, 236041 Kaliningrad, Russia
}

\begin{abstract}
The relevance of the philosophy of sustainable development of modern society has imposed a certain responsibility on the education sector as one of the main factors in the transformation of public consciousness in the context of social and economic self-fulfillment as a tool for forming an integrated approach to the problems of environmental safety, social equality and economic development of the world community. The article deals with the main aspects of the necessary modernization and transformation of the educational environment in Russia to ensure sustainable development and achieve the Millennium Goals. An attempt was made to assess the implementation of the National Education Strategy for Sustainable Development, for a number of activities and their implementation in the context of modern domestic practice. As a conclusion, the need is stated to modernize the modern educational environment through the prism of rational government decisions at each level of administration.
\end{abstract}

\section{Introduction}

Modern features of the development of socio-economic relations are undergoing serious changes under both global trends and the current shock epidemiological situation, which in turn has a direct impact on the state and trajectory of the educational environment and educational space. The educational environment is known as a fairly dynamic element of modern society, as well as its indicator, in terms of ensuring socially significant goals, including sustainable development ones. The role and importance of education can hardly be overestimated in ensuring the perception and implementation of the key parameters of the idea of sustainable development. In this regard, the significance of the state and nature of the transformation of the educational environment, which forms the attitude of the younger generation to the problems of sustainable development, is highly relevant.

Over the past 20 years, the ideas of sustainable development have become the key development paradigm of modern mankind. The actualization of environmental conservation and the formation of priorities for ensuring environmental safety during socioeconomic development received wide support in the world community and formed the basis of strategic documents at the level of entire states. The world community has unanimously recognized the need for a complete transformation of the main aspects of society's life,

\footnotetext{
* Corresponding author: inobbat@mail.ru
} 
namely, technical re-equipment, social and humanitarian principles and goals of public administration to achieve the sustainable development goals.

The founders of the Club of Rome and the concept of sustainable development proclaimed, primarily, the need to transform the modern way of thinking and tactics of human behavior in relation to such global problems as environmental pollution and the prevention of an ecological catastrophe, and quite clearly understood the significant role of education and awareness in the dissemination of rooting this idea in the world community. As noted in Chapter 36 "Promoting Education, Public Awareness and Training" of Agenda 21 , education and awareness are critical for sustainable development and the promotion of environmental ethics at every level of application. The use of formal and informal forms of education will make it possible to radically change the approaches of mankind to the problems of sustainable development, and will also increase the level of awareness on issues of ecology and environmental protection. [1] Thus, the need was indicated to radically revise educational technologies that would orient students to the possibility of rapid adaptation to rapidly changing environmental conditions from the standpoint of sustainable social, environmental and economic development.

The National Strategy for Education for Sustainable Development adopted in the Russian Federation in 2005 defines the transformation of the educational environment in such a way as to ensure the transition from simple methods and forms of knowledge transfer to innovative educational technologies capable of developing in students such skills and abilities that will enable them on the basis of a creative and independent approach to act most rationally in a rapidly changing environment, take part in planning social development, learn to foresee the consequences of actions taken, including in sustainability of natural ecosystems and social structures [2].

\section{Materials and Methods}

The transformation of the educational environment on the way to sustainable development presupposes the formation of such a Russian society that follows all spiritual, moral, historical, and universal principles of conscious evolutionary development for the benefit of present and future generations.

And according to the state policy in education, the modernization of the Russian educational environment to ensure sustainable growth involves a number of approved measures and areas of action. In particular:

- ensuring equal access of all categories of the population, all administrative territories of the Russian Federation to quality economic, social, and environmental education;

- dissemination of the principles of sustainable development through mediated sources of formal and informal education;

- development of a multicultural approach to the formation of educational trajectories, considering the traditions and cultures of the peoples of Russia;

- expanding the possibilities of using distance education;

- inclusion of subjects that form competencies in sustainable development in curricula;

- promotion of interest in education for sustainable development;

- ensuring academic mobility through the consistency of educational programs on a national, European, and global scale;

- increasing the level of competence of civil servants in sustainable development [2]. 
The availability of high-quality economic, social and environmental education is ensured through the provision of budgetary places in the listed areas of educational programs. In 2019, the Government adopted the trajectory of reducing the number of budget places in areas of humanitarian training, but current year has made adjustments and the number of budget places for the 2020-2021 academic year was increased by 30 thousand places. At the same time, such undergraduate programs as Theology $(+19.53 \%)$, Nursing $(+18.57 \%)$, Cultural studies and socio-cultural projects $(+18.13 \%)$, Arts $(+12.69 \%)$, and Information security $(+11.24 \%)$ received budgetary funding. Also, according to the information of the official statistics bodies, among the specialties for which the state funding was increased are "Informatics and Computer Engineering" (+ $6.53 \%$, total 29,718 places), "Education" ( $+3.44 \%$, total 48,106 places), as well as "Mechanical engineering" (+ 2.75\%, 14,561 places), and "Electric power engineering" (+ $0.75 \%, 14,884$ places). The number of budget places for specialties and bachelor's programs in Economics and Management decreased by almost $11 \%$. This fact, however, does not shorten the demand for these areas of training among applicants, and today the rating of the most popular areas among applicants is presented by jurisprudence, economics and management, as well as information and computer technologies.

In recent years, the promotion of training programs for specialists in environmental protection measures and technosphere safety has been intensified, which is primarily due to the growing demand for specialists in this field, as many industrial enterprises have completely revised the principles of organizing production in accordance with environmental standards and requirements. Leading universities of the country are implementing educational bachelor and master's programs in environmental education and culture, environmental protection and vital activity of ecosystems. Particularly relevant areas of training are interdisciplinary areas that combine, for example, bioengineering and environmental education, as well as legal and environmental safety, etc.

We would also like to note the growth in the number of applicants to the specialties in Sociology. Here, the choice of applicants is influenced by the formation of a positive image of the professional environment of such specialists, which is caused by the objective conditions of the development of modern society. Attention should be paid to the demand on the labor market for specialists of this profile, which in turn is explained by the growth of social tension in society and the social responsibility of business and the state.

Thus, in Russian practice, the peculiarities of the dissemination of economic, environmental, and social knowledge are reduced to the fact that the young generation, through the formation of their choice and preferences of educational programs, contributes to an increase in the economic, environmental, and social literacy of the population. The role of the state, for the most part, comes down to reforming educational standards that contribute to higher academic freedom and choice of forms and methods of study. Separately, we should dwell on the National project on improving financial literacy among the population, which is being implemented by the Ministry of Economic Development and the Center for Continuing Education of Lomonosov Moscow State University.

The spread of the principles of sustainable development through the use of formal and informal forms of education began in 1994, when more than 250 European universities signed the University Charter for Sustainable Development. According to this document, higher educational institutions have focused on the interdisciplinary nature of educational and research programs at the junction of environmental education, since the environmental principles of organizing economic and social life imply penetration into almost all spheres and sectors of the economy. Also, this trend was due to the existing experience in the provision of environmental education in European countries, namely through the system of integration of ecology, economics, and politics. At the same time, it was the spread and 
popularization of environmental education that contributed to the deeper penetration of the principles of informal education into the educational process.

As noted above, the use of education to achieve sustainable development requires a reorientation and a shift in emphasis from the process of "transfer and provision of knowledge" in a reproductive form to informal teaching methods, which will help students develop competencies to work out problems and find possible solutions, that is to the model of problem-based learning and alternative solutions [3].

Here, we should also speak about the change in educational policy in the context of the spread of forms of informal education and the erasure of educational boundaries. In particular, according to M. Larionova, European educational systems began their transformation through deepening interaction between the education sector, the labor market, and other stakeholders, which significantly expanded the educational framework and made it possible to improve the quality of education in general [4]. It should also be noted that this approach allowed expanding the possibilities of networking and facilitated the exchange of academic experience at all levels of the educational organization, up to the organization of academic mobility programs for students, to joint educational programs.

With regard to Russian practice, the spread of informal education is also due to the objectively developed environment, which, within modern requirements for the quality of education, keeps current such methods of acquiring information, knowledge, skills, and experience as participation in project research circles, participation in international or allRussian scientific and practical conferences. In addition, practice-oriented educational programs or applied bachelor's programs are widely spread. Learning through immersion in a problematic environment, modeling business situations, as well as the use of group decision methods allows students to develop skills and knowledge for quick adaptation to changes in the external environment, the ability to predict the situation and make rational decisions.

The multinational nature of the Russian population leaves its own trace on the formation of the educational environment and its basic elements. Achieving the main goals of the millennium development directly presupposes education within the framework of a multicultural environment, when the equality of all cultures is proclaimed with a support to a tolerant attitude towards cultural diversity and differences and complete exclusion of racism, totalitarianism, as well as any national, religious, gender and other discrimination. And of course, the formation of a multicultural, tolerant educational environment is a paramount issue for multi-ethnic and multi-confessional Russia, where representatives of 193 nationalities and ethnic groups live, has over 70 religious movements, successors of which differ in religion, culture, history, and have their own system of values. According to the Strategy of the state national policy of the Russian Federation until 2025 adopted in 2012, 277 languages and dialects are used in the country, 89 languages are used in the state education system, 30 of which are used as the language of teaching, and 59 - as a subject of study" [5]. This aspect is reflected in the educational environment through the inclusion of social competence, which is formed and manifested through the ability to make group decisions, the ability to nonviolent decisions and tolerance of views. The formation of such educational programs that, when mastered, will allow the graduate to convey the ethnocultural heritage in the context of Russian and world civilization through the principles of dialogue and interaction of cultures is an essential condition for achieving sustainable development goals.

The expansion of the possibilities of distance learning is primarily associated with the evolution of technologies and their application in the educational process. The current epidemiological situation in the world made it necessary to radically revise the distance learning format as an alternative. An increasing number of experts in education express doubts about the need to preserve the traditional form of education for certain areas of 
training. At the same time, it is not yet necessary to speak about the complete replaceability of the traditional form of distance learning. This is primarily due to the different level of technological equipment in the field of ICT in the regions and constituent entities of the Russian Federation, as well as the capabilities of students to ensure the appropriate quality of technical equipment. At the same time, the expansion of remote technologies in the educational environment will make it possible to form the skill of independent work and self-organization of students, as the process of control over learning is completely vested from the teacher in the students themselves, developing their responsibilities for selfeducation and self-discipline.

If we consider the possibilities of spreading distance learning in terms of academic mobility and the possibility for students to independently form their educational trajectory, then this format is more than justified. Also, today, in the context of digital transformation and the formation of a digital educational space, the possibilities of distance education are even greater than that of the traditional one. The world's leading educational institutions have formed meaningful educational platforms, which provide all types and tools for obtaining and monitoring knowledge, as well as the possibility of working out the acquired skills in the process of distance learning.

In recent years, the regulatory framework for the implementation of the educational process has been undergoing active reforming, which undoubtedly has an impact on the educational environment itself. In particular, the allocation of academic and practical training of students of graduate education, the formation of interdisciplinary training programs, as well as the use of a competence-based approach in the formation of basic educational programs allows including disciplines in the curricula that can form the necessary competencies in the field of sustainable education. Many universities have decided to include a discipline such as Green Economy, which forms a consistent knowledge of the theory and practice of sustainable growth and development. An equally relevant training module can be Environmental Law, dedicated to the study of the regulatory and legal framework for ensuring the environmental safety of business entities at every level, from an enterprise to an industry complex and department. If we consider the training programs for graduate students, today specialized training of qualified specialists in sustainable development is being implemented, both within the framework of the implementation of state policy and management, and the organization of management at enterprises.

Thus, the modern domestic educational environment is almost completely focused on spreading interest in obtaining a degree in sustainable development. Also, we would like to note the consistency and levelness of this trend. In our opinion, it is necessary to introduce educational initiatives for sustainable development at the level starting with preschool education, within the framework of school education to form knowledge and skills in environmental ethics and culture of behavior of human and society, with an emphasis on the results of human activities as the cause of environmental disasters. University education should be focused on the provision of deeper and more specialized knowledge, skills and abilities in the chosen training profile. Accordingly, the formation of a culture of environmental human behavior in society is one of the most relevant educational programs, the implementation of which should be consistent and systematic [7].

As defined above, sustainable development presupposes high academic mobility in sharing experience and implementing joint educational programs at every level, namely, on the all-Russian, European and global scales. The most actively implemented are joint master's training programs, since they involve a shorter educational trajectory in a narrow specialization and training profile. Russian universities are quite active in implementing joint educational programs with European graduate schools. 
And finally, the most important direction in modernization of the educational environment and transformation of the educational space is increasing the level of competence of civil servants in sustainable development. Within the framework of this direction, professional development programs are being implemented among civil servants of special ministries and departments, including in green economic growth, social equality and stability, as well as environmental knowledge, culture, and law.

\section{Results and Discussion}

The study of issues on the implementation of the concept of sustainable growth in Russian practice is a highly relevant area of research. As a number of scientists in disseminating the principles of sustainable development considers, sustainable development itself is not a goal, but a specially organized form of social life [8], which is aimed at reducing disparities in international and social relations, economics, and dynamics of biospheric processes and the state of ecosystems, and the priority of determining each of the aspects depends on the target indicators and the initial functioning conditions.

\section{Conclusions}

The modern Russian educational environment acts as a fundamental factor in the spread of culture and policies in the field of sustainable growth. The implemented state policy, should primarily be aimed at fostering a humanistic world view and socialization of environmental management, as well as the formation of rational economic thinking on the basis of greening society. As the study has shown, the process of forming sustainable education, in general, the development trajectory correlates with the target indicators and contributes to their achievement. However, there are a number of urgent issues, which solution will definitely contribute to a more progressive sustainable growth of Russian society and economy.

\section{References}

1. Agenda for the XXI century. Rio de Jane Declaration on Environment and Development. Adopted by the United Nations Conference on Environment and Development, Rio de Janeiro, 3-14 June (1992), https://www.un.org/

2. National Education Strategy for Sustainable Development in the Russian Federation, United Nations European Economic Commission, http://www.unece.org/

3. Russia in the world around it: 2010, Sustainable Development: ecology, politics, economics: analytical yearbook, 352 (2010)

4. M.V. Larianova, Bulletin of international organizations. Education, Science, New Economy, 2(1), 4(2007)

5. Decree of the President of the Russian Federation of 19.12.2012 No. 1666. On the Strategy of the State National Policy of the Russian Federation until 2025.

6. A.P. Shadrikova, Bulletin of International Organizations, Education, science, new economy, 5(4), 29 (2010)

7. E. Unterhalter, International Journal of Educational Development, 25, 111 (2005)

8. Modernization of Russian education: problems and prospects (2010) 